\title{
Anti-Inflammatory, Antioxidant, and Anthelmintic Activities of Ocimum basilicum (Sweet Basil) Fruits
}

\author{
Clement Osei Akoto $\mathbb{D}^{1},{ }^{1}$ Akwasi Acheampong ${ }^{(D)},{ }^{1}$ Yaw Duah Boakye ${ }^{D},{ }^{2}$ Abdulai A. Naazo, ${ }^{1}$ \\ and Derrick H. Adomah ${ }^{1}$
}

${ }^{1}$ Department of Chemistry, Faculty of Physical and Computational Sciences, College of Science, Kwame Nkrumah University of Science and Technology (KNUST), Kumasi, Ghana

${ }^{2}$ Department of Pharmaceutics, Faculty of Pharmacy and Pharmaceutical Sciences,

Kwame Nkrumah University of Science and Technology, Kumasi, Ghana

Correspondence should be addressed to Clement Osei Akoto; cakoto@hotmail.com

Received 8 August 2019; Revised 21 December 2019; Accepted 29 January 2020; Published 23 May 2020

Academic Editor: Maria C. Yebra-Biurrun

Copyright $(2020$ Clement Osei Akoto et al. This is an open access article distributed under the Creative Commons Attribution License, which permits unrestricted use, distribution, and reproduction in any medium, provided the original work is properly cited.

\begin{abstract}
Basil (Ocimum basilicum Linn.) is a plant that has found use in traditional medicine and household remedy against human ailments. The present study aimed at investigating hexane and ethanol fruit extracts of Ocimum basilicum Linn. for their phytoconstituents and anti-inflammatory, antioxidant, and anthelmintic activities. Phytochemical screenings were performed using standard protocols. Anti-inflammatory activities were assessed using the egg albumin denaturation method, while the antioxidant activities of the extracts were determined using DPPH scavenging, total antioxidant capacity (TAC), and hydrogen peroxide $\left(\mathrm{H}_{2} \mathrm{O}_{2}\right)$ assays. In vitro anthelmintic activity of both extracts was investigated against Eudrilus eugeniae (Earthworms). Column chromatography was employed to separate the least polar fraction A, using hexane as the mobile phase, which was analyzed using FTIR analysis. The preliminary phytochemical screening revealed the presence of alkaloids, phenols, saponins, glycosides, steroids, tannins, terpenoids, and flavonoids. The hexane and ethanol extracts exhibited high concentration-dependent anti-inflammatory activities, with their percentage inhibitions being $34.0 \pm 0.01$ and $17.6 \pm 0.04 \mu \mathrm{g} / \mathrm{mL}$, respectively. The hexane extract showed a higher concentration-dependent antioxidant activity $\left(\mathrm{IC}_{50}\right.$ of $\left.14.17 \pm 1.15 \mu \mathrm{g} / \mathrm{mL}\right)$ compared to the ethanol extract $\left(\mathrm{IC}_{50}>100.0 \mu \mathrm{g} / \mathrm{mL}\right)$ for the DPPH assay. The $\mathrm{IC}_{50}$ values of ethanol and hexane extracts were $623.5 \pm 0.27$ and $>1000.0 \mu \mathrm{g} / \mathrm{mL}$, respectively, for the $\mathrm{H}_{2} \mathrm{O}_{2}$ scavenging assay. TAC was determined to be $37.48 \pm 0.09$ and $18.81 \pm 0.12 \mathrm{gAAE} / 100 \mathrm{~g}$ for ethanol and hexane extracts, respectively. Both extracts showed a higher concentration-dependent anthelmintic activity. Increasing the concentration increased the helmintic potency of the extracts. The results indicate that both hexane and ethanol extracts of Ocimum basilicum Linn. exhibit anti-inflammatory, antioxidant, and anthelmintic activities and support the traditional usage of this plant.
\end{abstract}

\section{Introduction}

The use of natural products from plants by humans for treatment of various ailments could be traced back to the middle of Paleolithic era, which is about 60,000 years ago according to fossil records [1]. Medicinal plants, otherwise referred to as herbs or herbal medicine, are the richest of bioresource of drugs of traditional systems of medicine, modern medicines, nutraceuticals, food supplements, folk medicines, pharmaceutical intermediates, and chemical entities for synthetic drugs [2]. According to World Health
Organization, between 70 and $95 \%$ of the population in developing countries rely on plants for their primary health care [3]. From the estimated 300,000 plants species that exist in the world, only $15 \%$ have been investigated for their pharmacological potential indicating the need for research into plant medicine $[4,5]$. Many plants have been identified to exhibit antimicrobial, antioxidant, and anti-inflammatory activities $[6,7]$.

Helminthiasis is a disease that affects both man and animals leading to stunted growth. In developing countries, it poses a great threat to public health and contribute to the 
prevalence of malnutrition, anemia, eosinophilia, and pneumonia [8]. Helminth infection is one of the most common diseases in the world, especially in the tropical regions. Recent estimates of the World Health Organization (2019) suggest that about 1.5 billion people suffer helminthiasis [9]. This infection poses a great threat to both human and animal health and is most prevalent in tropical and subtropical areas, with the greatest numbers occurring in sub-Saharan Africa, the Americas, China, and East Asia. Anthelmintics are a group of antiparasitic drugs that expel parasitic worms (helminths) and other internal parasites in the body by either stunning or killing them and without causing significant harm to the host [10]. However, resistance is probably an inevitable consequence of the use of anthelmintics, and the history of parasite resistance to anthelmintic starts with the first report on phenothiazine in 1957 by nematodes of Haemonchus contortus [11].

Basil or sweet basil (Ocimum basilicum) belongs to the genus Ocimum, with local names in Ghana as Nunum in Akan language and Nyulin-nyuu in Dagbani language. Its name was derived from the Greek word Ozo which means to smell, in reference to the strong odours of the species within the genus [12]. Ocimum basilicum (sweet basil) is ubiquitously known for its therapeutic potentials in folk medicine. Folk medicine practitioners in Northern part of Ghana use the fruits of Ocimum basilicum against ailments such as worm infestation, inflammations, diarrhoea, and eye-related diseases according to the oral survey conducted by our research laboratory. In Annam, an infusion of the plant of Ocimum basilicum is considered to be anthelmintic, diaphoretic, antiemetic, and antidiarrhoeaic [13, 14]. Other parts of the plant are used against infections, impotency, hypertension, pains, and diabetes, among others [13, 14].

Khare reported that Ocimum basilicum plant contains flavonoids and phenolic compounds, and its green leaves are enriched with high concentration of vitamins, minerals, and oils [15]. The fresh flowering herb of Ocimum basilicum yields essential oil containing small amount of eucalyptol, estragol, ocimene, linalool, eugenol, acetate, 1-epibicyclosesquiphellandrene, methanol, menthone, cyclohexanol, cyclohexanone, myrcenol, and nerol [16]. Phytochemical screening conducted by Bihari et al. on Ocimum basilicum aerial parts showed the presence of flavonoids, phenolic compounds, protein, amino acids, glycoside, gums, mucilage, tannins, flavones, triterpenes, steroids, and saponin [17]. Research conducted by Razavi et al. revealed that basil seeds contain a gum, which comprises two major fractions of glucomannan (43\%) with the ratio of glucose to mannose 10:2 and $(1 \longrightarrow 4)$-linked xylan $(24.29 \%)$ and a minor fraction of glucan (2.31\%) [18]. Azuma and Sakamoto also reported the presence of highly branched arabinogalactan in addition to glucomannan and $(1 \longrightarrow 4)$-linked xylan [19].

Hence, this research study is tailored to find new leads for anthelmintic agents that are bioactive, efficacious, and safe to combat the resistance developed by parasitic helminths $[13,14]$. Ocimum basilicum fruits can be a potential source for new anthelmintics based on its versatile therapeutic application in folk medicine for worm infestation in Northern parts of Ghana and anthelminthic usage in Annam $[13,14]$; hence, it is worth much in ascertaining the claims by herbalist and local medical practitioners for the potency of Ocimum basilicum fruits.

Most research studies conducted on the pharmacological potential of Ocimum basilicum were mainly focused on crude extracts of the leaves, roots, and stem bark. Nevertheless, it is also important to identify the bioactive compounds responsible for each one of the ascribed bioactivities, especially for the fruits. At the time of carrying out this research, there are no reports on the anthelmintic activity of this plant.

The aim of this study was, therefore, to examine the efficacy of $O$. basilicum ethanolic and hexane fruit extracts as an anthelmintic as well as to confirm the anti-inflammatory and antioxidant activity previously reported $[20,21]$ using in vitro assays. Additionally, it is aimed at identifying and confirming the presence of the phytochemicals in the fruit extract, eliciting pharmacological activities using FTIR analysis.

\section{Materials and Methods}

2.1. Sample Collection and Identification. The fruits of $O$. basilicum (basil) were collected at Gurugu in the Sagnarigu District of Northern Ghana (latitude: $9^{\circ} 16^{\prime} \mathrm{N}-9^{\circ} 34^{\prime} \mathrm{N}$ and longitude: $0^{\circ} 36^{\prime} \mathrm{W}-0^{\circ} 57^{\prime} \mathrm{W}$ ) with the help of a local herbalist between 18 and 20 September 2018. The fruits were identified by Mr. James Amalgon at the Forestry Department in Tamale. The fruits were further taxonomically identified and authenticated by Mr. Clifford Osafo Asare at the Department of Herbal Medicine, Faculty of Pharmacy and Pharmaceutical sciences, Kwame Nkrumah University of Science and Technology (KNUST). Voucher specimen (KNUST/HMI/2019/S001) was deposited in the herbarium for reference purposes.

2.2. Chemicals and Reagents. All chemicals were purchased from Sigma Aldrich Co. Ltd., Irvine, U.K., except the standard drugs. The organic solvents were of analytical grade and procured from BDH Laboratory Supplies (England).

2.3. Extraction of Plant Material. The fruits of O. basilicum were thoroughly washed, first under running water to remove any form of debris, and subsequently rinsed in distilled water to exclude heavy metals in tap water. The fruits were air-dried under shade for two weeks, pulverized into coarse powder, and stored in a desiccator until analysis.

2.3.1. Preparation of Ethanol and Hexane Extracts. A mass of $100 \mathrm{~g}$ of the powdered sample of O. basilicum was soaked separately in $1 \mathrm{dm}^{3}$ of ethanol and hexane and extracted using the Soxhlet apparatus over 8 hours until the sample was completely exhausted [7]. The ethanol and hexane extracts were condensed and evaporated to dryness using the rotary evaporator at $50^{\circ} \mathrm{C}$ (BUCHI Rota vapor R-114). The extracts were dried, and the percentage yield of extracts with respect to powdered plant material was determined. The extracts were then stored at $4^{\circ} \mathrm{C}$ in a refrigerator. 
2.4. Phytochemical Screening of Extracts. The pulverized sample and the crude extracts (ethanol and hexane) obtained were screened to assess the presence of phytoconstituents using the methods described by Trease and Evans [22].

2.5. Collection of Eudrilus eugeniae for Anthelmintic Activity. Earthworms (Eudrilus eugeniae) were collected from a water logged area behind the Department of Theoretical and Applied Biology within KNUST, Kumasi-Ghana (latitude $6^{\circ} 35 \mathrm{~N}-6^{\circ} 40 \mathrm{~N}$ and longitude $1^{\circ} 30 \mathrm{~W}-1^{\circ} 35 \mathrm{~W}$ ). The worm type was authenticated at the Zoology Unit, Department of Theoretical and Applied Biology, KNUST, by Mr. Lawrence Yeboah.

2.5.1. In Vitro Anthelmintic Assay. In vitro anthelmintic activity against Eudrilus eugeniae (earthworms) of both ethanol and hexane extracts was examined. The anthelmintic assay was carried out using a modification of the methods described by Ajaiyeoba et al. [23]. Stock solutions of $5000 \mu \mathrm{g} / \mathrm{mL}$ of extracts and mebendazole (reference drug) were prepared using sterile distilled water as a solvent. From the stock solution, four concentrations of 250,500,1000, and $3000 \mu \mathrm{g} /$ $\mathrm{mL}$ were prepared. Saline water was used as a negative control. All the test solutions including the standard reference drug were freshly prepared before the start of the experiment. Three worms of approximately the same size were released into separate Petri dishes containing $50 \mathrm{~mL}$ each of the various test solutions.

Determination of time of paralysis and time of death of the worms were recorded. Time of paralysis was noted when no movement of any sort could be observed except when the worms were shaken vigorously. Time of death of worms was recorded after ascertaining that worms neither moved when shaken vigorously nor when dipped in warm water $\left(50^{\circ} \mathrm{C}\right)$ followed by fading away of their body colors. The experiment was independently repeated to obtain three independent sets of data for the analysis, and the results are expressed as a mean \pm standard error of the mean (SEM) $(N=3)$.

2.6. In Vitro Anti-Inflammatory Assay Using Egg Albumin Denaturation. Anti-inflammatory assay was carried out according to a modification of the methods described by Sree Kumari et al. [24]. The egg denaturation assay was employed in this study due to the fact that anti-inflammatory agents have been reported to inhibit thermal denaturation of proteins [24]. Stock solutions of $5000 \mu \mathrm{g} / \mathrm{mL}$ of both extracts were prepared by using sterile distilled water as a solvent. From the stock solutions, various concentrations of 1000 , 2000,3000 , and $4000 \mu \mathrm{g} / \mathrm{mL}$ were prepared using sterile distilled water as a solvent. The reaction mixtures of total volume $5 \mathrm{~mL}$ were prepared by dissolving $0.2 \mathrm{~mL}$ of egg albumin (fresh egg of a hen), $2.8 \mathrm{~mL}$ of phosphate-buffered saline (PBS, $\mathrm{pH}$ of 6.4 ), and $2 \mathrm{~mL}$ of the various concentrations of extract solutions. A volume of $2 \mathrm{~mL}$ of aspirin with similar varying concentrations as that of extracts was used as the standard reference drug and $2 \mathrm{~mL}$ of doubled distilled water solution served as negative control. The mixtures were incubated at $37^{\circ} \mathrm{C}$ in a Bio-Oxygen Demand (BOD) incubator for 15 minutes.

The mixtures were then heated in a water bath at $70^{\circ} \mathrm{C}$ for 5 minutes to induce denaturation. The absorbance of the solutions was measured in triplicate at $660 \mathrm{~nm}$ using UV-Vis spectrophotometer. The procedure was independently repeated to obtain three independent sets of data for the analysis in triplicate.

The percentage inhibition of protein denaturation was calculated as follows:

$$
\% \text { inhibition }=\frac{A_{0}-A}{A_{0}} \times 100,
$$

where $A_{0}=$ absorbance of negative control and $A=$ absorbance of test solution.

2.7. In Vitro Antioxidant Assays. Three main assays were employed for the antioxidant activity determination. They were 1,1-diphenyl-2-picrylhydrazyl (DPPH) free radicals scavenging, hydrogen peroxide scavenging, and the total antioxidant capacity assays.

2.7.1. DPPH Radical Scavenging Assay. The free radical scavenging activity of ethanol and hexane extracts was examined according to a modification of the methods described by Sánchez-Moreno et al. [25]. A solution of $20 \mu \mathrm{g} / \mathrm{mL}$ DPPH was prepared by dissolving $2 \mathrm{mg}$ of DPPH in $100 \mathrm{~mL}$ of methanol. Stock solutions of $100 \mu \mathrm{g} / \mathrm{mL}$ of each extract in dimethyl sulfoxide (DMSO) were prepared from which various concentrations $50,25,12.5$, and $6.25 \mu \mathrm{g} / \mathrm{mL}$ were prepared using DMSO as solvent. A stock solution of $100 \mu \mathrm{g} / \mathrm{mL}$ ascorbic acid was also prepared from which various concentrations $50,25,12.5$, and $6.25 \mu \mathrm{g} / \mathrm{mL}$ were made through serial dilution using distilled water as a solvent. Ascorbic acid was used as a reference standard. The reaction mixtures of volume $200 \mu \mathrm{L}$ were prepared by dissolving $150 \mu \mathrm{L}$ of $20 \mu \mathrm{g} / \mathrm{mL}$ DPPH solution and $50 \mu \mathrm{L}$ of various concentrations of the test solutions. The mixtures were then incubated in dark at room temperature for 30 minutes, after which the absorbance was measured at $517 \mathrm{~nm}$. The experiment was independently repeated to obtain three independent sets of data for the analysis. DPPH radical scavenging (\%) was calculated using the following formula:

$$
\% \text { scavenging }=\frac{A_{0}-A}{A_{0}} \times 100 \%,
$$

where $A_{0}=$ absorbance of control and $A=$ absorbance of test solution.

2.7.2. Hydrogen Peroxide Scavenging Assay. Determination of hydrogen peroxide scavenging potential of ethanol and hexane extracts was carried out according to a modification of the methods described by Mukhopadhyay et al. [26]. The assay is based on specific complexation of ferrous ion with 1,10-phenanthroline to form red-orange triphenanthroline complex. 
Stock solutions $(1000 \mu \mathrm{g} / \mathrm{mL})$ of each extract in sterile distilled water were diluted to produce concentrations of 200, 400, 600, and $800 \mu \mathrm{g} / \mathrm{mL}$. For the standard, a stock solution of $500 \mu \mathrm{g} / \mathrm{mL}$ of gallic acid was prepared, from which various concentrations ranging from 10 to $250 \mu \mathrm{g} / \mathrm{mL}$ were obtained by dilution.

To a series of test tubes, $0.5 \mathrm{~mL}$ of ferrous ammonium sulphate $(1 \mathrm{mM})$ was added. Then, $3 \mathrm{~mL}$ of test solutions (various concentrations of both the extracts and gallic acid solutions) was added and mixed. A volume of $0.13 \mathrm{~mL}$ hydrogen peroxide at a concentration of $5 \mathrm{mM}$ was added and thereafter incubated at room temperature in dark (because hydrogen peroxide can be photo bleached) for 5 minutes. After incubation, $3 \mathrm{~mL}$ of $1 \mathrm{mM} 1,10$-phenanthroline was added to each tube, mixed well, and incubated for 10 minutes at room temperature. Finally, absorbance was taken at $510 \mathrm{~nm}$ using a UV-Vis spectrophotometer. The negative control contained only ferrous ammonium sulphate $(0.5 \mathrm{~mL}$ and $1 \mathrm{mM})$, distilled water $(3 \mathrm{~mL})$, and 1,10 phenanthroline $(3 \mathrm{~mL}$ and $1 \mathrm{mM})$. The experiment was independently repeated to obtain three independent sets of data for the analysis. The percentage scavenging activity was calculated using the following formula:

$$
\% \text { scavenging }=\frac{A_{\text {test }}}{A_{\text {control }}} \times 100,
$$

where $A_{\text {test }}$ is absorbance of the test samples and $A_{\text {control }}$ is the absorbance of the negative control. The results were further reported in $\mathrm{IC}_{50}$.

2.7.3. Total Antioxidant Capacity (TAC) Assay. A modification of the methodology described by Prieto et al. was used to study the total antioxidant capacity of the ethanol and hexane extracts of $O$. basilicum [27]. The method is based on the reduction of phosphomolybdic acid, Mo (VI) to phosphomolybdenum, Mo (V) blue complex by the extracts, and standard reference. Ascorbic acid was used as the reference standard, and distilled water was used as the blank. A stock solution of $100 \mu \mathrm{g} / \mathrm{mL}$ of ascorbic acid was prepared from which concentrations of $50,25,12.5$, and $6.125 \mu \mathrm{g} / \mathrm{mL}$ were prepared through serial dilution using sterile distilled water as solvent. A test solution of concentration of $500 \mu \mathrm{g} / \mathrm{mL}$ of each extract in sterile distilled water was also prepared.

Reaction mixtures of total volume of $10 \mathrm{~mL}$ were prepared from $5 \mathrm{~mL}$ of test solution mixed with $5 \mathrm{~mL}$ phosphomolybdenum (0.6 M sulfuric acid, $28 \mathrm{mM}$ sodium phosphate, and $4 \mathrm{mM}$ ammonium molybdate) in series of test tubes. The mixtures were then incubated in a water bath at $95^{\circ} \mathrm{C}$ for 90 minutes.

The absorbances of each of the solutions were then measured in triplicate, using the UV-visible spectrophotometer at $695 \mathrm{~nm}$ after cooling. The experiment was independently repeated to obtain three independent sets of data for the analysis. A plot of the measured absorbance of the ascorbic acid solutions against their concentrations was made to obtain the calibrated concentration-absorbance curve of the ascorbic acid using Microsoft excel. The absorbances of the extract solutions were then substituted for the dependent variable in the linear equation of the ascorbic acid concentration-absorbance plot to determine their corresponding independent variables as ascorbic acid equivalents (AAE), expressed as gAAE/100 g ascorbic acid.

2.8. Thin Layer Chromatography (TLC). The number of phytoconstituents present in the extracts was determined by the analytical TLC method. The precoated silica gel plates $(0.25 \mathrm{~mm})$ with a fluorescent indicator (F254) were spotted with the ethanol and hexane extracts about $1 \mathrm{~cm}$ from the bottom edge of plates, with the aid of capillary tubes and allowed to dry [28]. Various solvent systems of petroleum ether/ethyl acetate and hexane/ethyl acetate in the ratio of 9 : 1 and $8: 2$, respectively, were used. The ratio of $9: 1$ (hexane/ ethyl acetate) gave the best separation of components for all the extracts. The plates were dried and visualized by a $254 \mathrm{~nm}$ UV lamp. The separated spots were then marked, and their sample and solvent fronts were measured.

The retardation factor $\left(R_{\mathrm{f}}\right)$ of the eluted spots was calculated as follows:

$$
R_{\mathrm{f}}=\frac{\text { distance travelled by spot }}{\text { distance travelled by solvent front }} .
$$

This solvent system was then adapted and used in column separation.

2.9. Column Chromatographic Separation. Flash chromatography was performed using $40-63 \mu \mathrm{m}$ silica gel $(200 \times 400$ mesh) to separate the number of components present in the extracts [29]. Dry powdered hexane extract was chromatographed on a column packed with silica gel and eluted with a gradient of solvent hexane to provide a fraction $\mathrm{A}$. The fraction was monitored by means of TLC (eluent hexane/ EtOAc, 9:1). The fraction was evaporated to dryness using the rotary evaporator, then dried, and stored at $4^{\circ} \mathrm{C}$ in a refrigerator until the use.

2.10. Fourier Transform Infrared Spectrometer (FTIR) Analysis. The dried fraction $(A)$ was subjected to FTIR analysis (UATR Two, PerkinElmer) to determine the functional groups present. The regions between $4000 \mathrm{~cm}^{-1}$ and $400 \mathrm{~cm}^{-1}$ were scanned, followed by baseline correction.

2.11. Data Analysis. Microsoft Excel 2016 and GraphPad Prism 6.0 for Windows (GraphPad Software, San Diego, CA, USA) were used for all data analyses and graphs.

\section{Results and Discussion}

3.1. Extraction of Plant Material. The yields of the extract in relation to the powdered plant material were calculated as percentages. The yields were 9.43 and $18.60 \%$ for ethanol and hexane extracts, respectively. 
3.2. Phytochemical Screening. The pharmacological activity of a plant depends on the phytochemical composition of the plant [22]. Phytochemical screening of $O$. basilicum revealed the presence of all nine secondary metabolites tested for in both the pulverized sample and the ethanol extract. The hexane extract showed the presence of eight secondary metabolites with the exception of alkaloids (Table 1).

The ethanol and hexane extracts had eight phytochemicals in common, that is, diterpenes, flavonoids, glycosides, phenols, saponins, steroids, tannins, and terpenoids. The presence of some phytoconstituents in the fruits of $O$. basilicum justifies the local use of this fruit for the treatment of various ailments [30]. The seeds are rich in flavonoids, phenols, and tannins, which are polyphenolic compounds that are biologically active against liver toxins, microorganisms, inflammation, tumor, and free radicals [31]. Secondary metabolites of plants which include terpenoids, flavonoids, phenolic acids, alkaloids, and steroids have been shown to exhibit various pharmacological activities such as wound healing, anti-inflammation, anticancer, antioxidant, immunomodulation, antidiarrhoeal, antimicrobial, antidepressant, hepatoprotective, antiplasmodial, and anxiolytic [32]. The presence of these phytochemicals in the ethanol and hexane extracts of $O$. basilicum indicate that they will play a key role in the prevention of various helminthic infections, inflammatory, and diseases associated with oxidative stress.

3.3. Anthelmintic Activity. Anthelmintic potential of the extracts was examined using earthworms, owing to their anatomical and physiological resemblance with that of intestinal roundworm parasites of human beings as well as their ease of availability [33]. Ethanol and hexane extracts and mebendazole (standard drug) displayed concentrationdependent anthelmintic activity at test concentrations of 5000 to $250 \mu \mathrm{g} / \mathrm{mL}$ (Table 2). The anthelmintic activities of ethanol and hexane extracts at test concentrations were observed to be significantly $(P<0.001)$ higher compared to mebendazole-treated worms.

The mode of action of some anthelmintics like piperazine citrate is to cause paralysis of worms such that they can be expelled in the faeces of man and animals [23]. The extracts did not only exhibit such potency but also caused death of the worms at a rate much higher than the standard drug mebendazole. The presence of the phytochemicals such as tannins, alkaloids, and terpenoids in the ethanol extract may be responsible for the high anthelmintic potency of the ethanol extract [34]. Although the hexane extract contains terpenoids and tannins, the absence of alkaloids which are known to be potent anthelmintics might be the cause of its lower anthelmintic potency compared to the ethanol extract.

In addition, tannins or their metabolites have direct effects on viability of the preparasitic stages of helminths [35]. Hence, the observed activity of the extracts could be attributed to the presence of tannins identified in this work, which could be exploited as therapy for the treatment of helminth infection due to their proposed ability to disrupt viability of the preparasitic stages of helminths [35].
TABle 1: Phytochemical constituents of the pulverized sample and extracts of O. basilicum.

\begin{tabular}{lccc}
\hline Phytochemical & $\begin{array}{c}\text { Pulverized } \\
\text { sample }\end{array}$ & $\begin{array}{c}\text { Ethanol } \\
\text { extract }\end{array}$ & $\begin{array}{c}\text { Hexane } \\
\text { extract }\end{array}$ \\
\hline Alkaloids & + & + & - \\
Diterpenes & + & + & + \\
Flavonoids & + & + & + \\
Glycosides & + & + & + \\
Phenols & + & + & + \\
Saponins & + & + & + \\
Steroids & + & + & + \\
Tannins & + & + & + \\
Terpenoids & + & +
\end{tabular}

Key. $+=$ presence of secondary metabolite; $-=$ absence of secondary metabolite.

3.4. In Vitro Anti-Inflammatory Assay (Egg Albumen Denaturation Method). Denaturation of proteins is a well-documented cause of inflammation and rheumatoid arthritis. Several anti-inflammatory drugs have shown concentrationdose-dependent ability to inhibit thermally induced protein denaturation [36]. The ability of plant extract to inhibit thermal denaturation of protein (egg albumin) is a reflection of its anti-inflammatory activity [36]. Ethanol and hexane extracts and aspirin (standard drug) displayed concentrationdependent anti-inflammatory activity at test concentrations of 5000 to $1000 \mu \mathrm{g} / \mathrm{mL}$ (Figure 1).

The ethanol and hexane extracts exhibited anti-inflammatory activity. However, at test concentrations for ethanol and hexane extracts, the anti-inflammatory activity was observed to be significantly higher $(P<0.01)$ than for aspirin (reference drug). The inflammatory activity of the extracts can be attributed to the presence of phenols, flavonoids, glycosides, terpenoids, and steroids present in O. basilicum, which have been reported to exhibit anti-inflammatory activity [20,21]. Flavonoids are known to inhibit enzymes as well as mediators of the inflammation process such as C-reactive protein or adhesion molecules [20].

3.5. Antioxidant Activity. The total antioxidant potential of a plant extract depends largely on both the constituent of the extract and the test system. Different factors can also influence the activity of the extract, and therefore, antioxidant capacity cannot be fully determined using only one method [37]. Considering the various mechanisms of antioxidant actions, the antioxidant properties of the extracts were evaluated by (DPPH) free radicals scavenging, hydrogen peroxide scavenging, and the total antioxidant capacity assays.

3.5.1. DPPH Radical Scavenging Capacity. The DPPH scavenging activity of the extracts was used to monitor the ability of the ethanol and hexane extracts of $O$. basilicum seeds to mop up free radicals that may be found in animals and humans. Ethanol and hexane extracts of $O$. basilicum and ascorbic acid (reference standard) of concentrations ranging between $6.25 \mu \mathrm{g} / \mathrm{mL}$ and $100 \mu \mathrm{g} / \mathrm{mL}$, scavenged DPPH radical at an absorbance ranging between $0.715 \pm 0.03$ and 
TABLe 2: Anthelmintic activity of ethanol and hexane extracts of O. basilicum.

\begin{tabular}{|c|c|c|c|c|c|c|}
\hline \multirow{3}{*}{ Concentration $(\mu \mathrm{g} / \mathrm{mL})$} & \multicolumn{6}{|c|}{ Mean paralysis and death time $(\min \pm \mathrm{SEM})$} \\
\hline & \multicolumn{3}{|c|}{ Paralysis time } & \multicolumn{3}{|c|}{ Death time } \\
\hline & Ethanol extract & Hexane extract & Mebendazole & Ethanol extract & Hexane extract & Mebendazole \\
\hline 5000 & $11.85 \pm 0.71^{*}$ & $27.90 \pm 0.42^{*}$ & $94.04 \pm 2.57^{*}$ & $24.74 \pm 0.42^{*}$ & $85.18 \pm 0.07^{*}$ & $522.77 \pm 1.53^{*}$ \\
\hline 3000 & $27.26 \pm 0.21^{*}$ & $90.82 \pm 1.32^{*}$ & $115.99 \pm 0.49^{*}$ & $53.61 \pm 0.09^{*}$ & $101.34 \pm 1.11^{*}$ & $565.42 \pm 0.84^{*}$ \\
\hline 1000 & $50.97 \pm 1.73^{*}$ & $93.37 \pm 2.90^{*}$ & $209.92 \pm 2.51^{*}$ & $79.8 \pm 0.32^{*}$ & $110.77 \pm 3.64^{*}$ & $600.92 \pm 0.22^{*}$ \\
\hline 500 & $72.84 \pm 1.33^{*}$ & $173.32 \pm 2.88^{*}$ & $218.72 \pm 0.71^{*}$ & $163.72 \pm 0.58^{*}$ & $301.72 \pm 0.61^{*}$ & $645.29 \pm 1.08^{*}$ \\
\hline 250 & $116.38 \pm 2.19^{*}$ & $215.34 \pm 4.09^{*}$ & $238.97 \pm 7.46^{*}$ & $213.39 \pm 1.05^{*}$ & $362.98 \pm 1.54^{*}$ & $654.66 \pm 1.45^{*}$ \\
\hline
\end{tabular}

Each time represents mean $\pm \operatorname{SEM}(N=3)$. The data were analyzed using one-way ANOVA compared to the mebendazole treatment. ${ }^{*} P$ value $<0.001$.

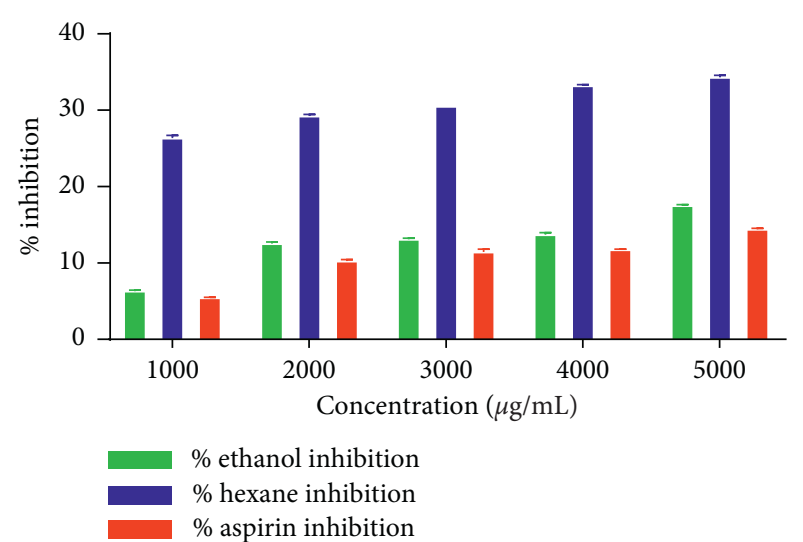

Figure 1: Percentage in vitro anti-inflammatory action of ethanol and hexane extracts of $O$. basilicum.

$0.7772 \pm 0.01,0.723 \pm 0.01$ and $0.753 \pm 0.02$, and $0.703 \pm 0.05$ and $0.848 \pm 0.03 \mathrm{~nm}$, respectively. Figure 2 shows the percentage inhibition of ethanol and hexane extracts and reference standard over a range of concentrations.

The hexane extract of $O$. basilicum showed the most potent concentration-dependent antioxidant activity with an IC $_{50}$ of $14.17 \pm 1.15 \mu \mathrm{g} / \mathrm{mL}$, compared to the ethanol extract $\left(\mathrm{IC}_{50}>100.0 \mu \mathrm{g} / \mathrm{mL}\right)$ for the DPPH assay (Table 3).

The results implied that the potency of the test samples of extracts as antioxidants decreased in the following order: hexane extract $>$ ethanol extract (Figure 2). The DPPH scavenging results show that $O$. basilicum fruit extracts may be useful in the manufacture of drugs to help prevent or cure health problems that could arise from the systemic actions of oxidative agents.

3.5.2. Hydrogen Peroxide Radical Scavenging Assay. Hydrogen peroxide radical scavenging potential of the ethanol and hexane extracts of $O$. basilicum was evaluated by the use of hydrogen peroxide $\left(\mathrm{H}_{2} \mathrm{O}_{2}\right)$ scavenging method. The results are shown in Figure 3.

The $\mathrm{IC}_{50}$ of a sample is the concentration required to scavenge $50 \%$ of the peroxide in a system. It is used to evaluate the antioxidant capacity of a sample. The lower the $\mathrm{IC}_{50}$, the better the antioxidant potential of the sample under examination [38]. The results showed that both ethanol and hexane extracts of $O$. basilicum demonstrated a significant antioxidant activity in concentration-dose dependent manner. The

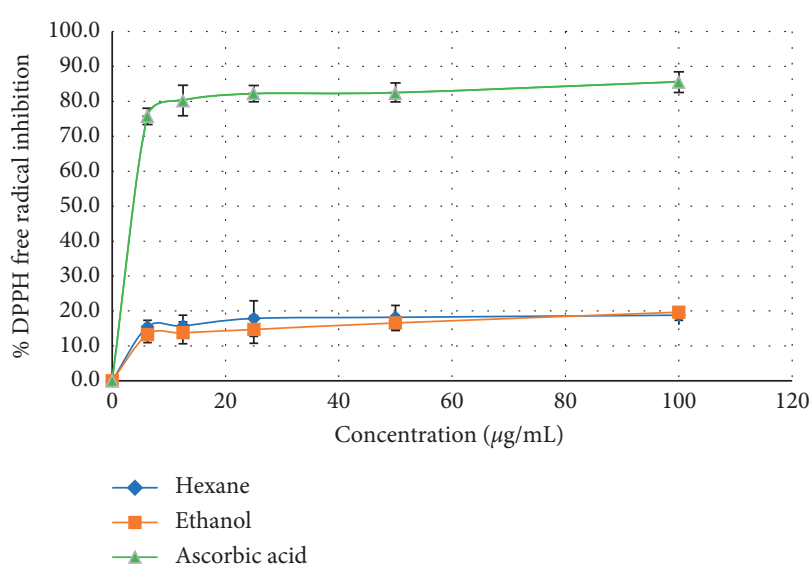

FIGURE 2: Comparative DPPH radical scavenging activity of the extracts of $O$. basilicum and ascorbic acid.

TABLE 3: $\mathrm{IC}_{50}$ of DPPH radical scavenging activity for the ethanol and hexane extracts of $O$. basilicum and ascorbic acid.

\begin{tabular}{lc}
\hline Sample & $\mathrm{IC}_{50}(\mu \mathrm{g} / \mathrm{mL})$ \\
\hline Standard (ascorbic acid) & $<6.25$ \\
Ethanol extract & $>100.0$ \\
Hexane extract & $14.17 \pm 1.15$ \\
\hline
\end{tabular}

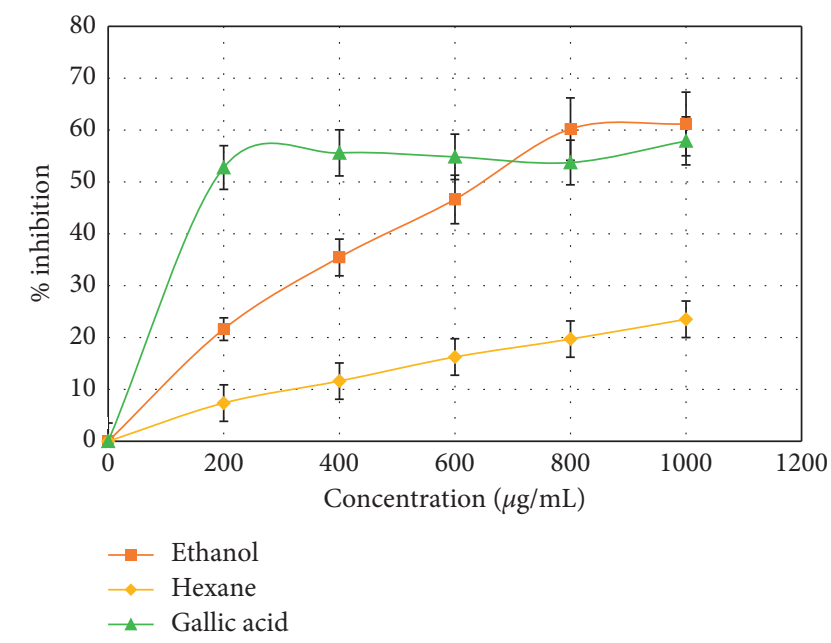

Figure 3: Hydrogen peroxide radical scavenging capacity of the extracts of $O$. basilicum and gallic acid. 
$\mathrm{IC}_{50}$ values of gallic acid (reference standard) and ethanol and hexane extracts were $204.4 \pm 0.65,623.5 \pm 0.27$, and $>1000.0 \mu \mathrm{g} / \mathrm{mL}$, respectively, as shown in Table 4 .

Hydrogen peroxide $\left(\mathrm{H}_{2} \mathrm{O}_{2}\right)$ is a ubiquitous, toxic metabolic by-product of aerobic respiration, oxidative stress, and oxidative injury. When left unquenched, $\mathrm{H}_{2} \mathrm{O}_{2}$ can react with ferric ions via the Fenton reaction to produce the hydroxyl radical, one of the most reactive and damaging free radical species known [39]. From the results, the bioactive isolates from these extracts responsible for antioxidant activity could be attributed to the flavonoids, phenols, and tannins present in O. basilicum and could be exploited for the treatment of diseases associated with oxidative stress [20].

3.5.3. Total Antioxidant Capacity (TAC). Ascorbic acid also known as vitamin $\mathrm{C}$ is an electron donor antioxidant, and this property is responsible for all its known functions. Vitamin $\mathrm{C}$ is a potent reducing agent and scavenger of free radicals in biological systems. It can donate electron to mop up or react with free reactive radicals and thus quench their reactivity [40].

Concentrations of ascorbic acid ranging between 6.125 and $100 \mu / \mathrm{mL}$ showed antioxidant activity and mean absorbances between $0.109 \pm 0.03$ and $0.932 \pm 0.02$ at a wavelength of $695 \mathrm{~nm}$ (Figure 4).

The TAC was found to be proportional to the concentration of extract. TAC of the extracts was examined by the phosphomolybdenum method, and the results were expressed as gram ascorbic acid equivalent per 100 grams (gAAE/100 g). The gAAE/100 g represents the fraction of the plant extract that can act as ascorbic acid in $100 \mathrm{~g}$ of the extract. The ethanol and hexane extracts had $37.48 \pm 0.09$ and $18.81 \pm 0.12 \mathrm{gAAE} / 100 \mathrm{~g}$, respectively (Table 5 ).

Generally, the TAC increased with increasing concentration; thus, the higher the TAC, the better the activity of the sample. Both extracts demonstrated appreciable antioxidant activities.

3.6. Thin Layer Chromatography (TLC). The number of components present in the extracts was determined by the analytical TLC method. The chromatographic spots which were representative of compounds in the various extracts were observed, and their $R_{\mathrm{f}}$ values were determined. Table 6 gives the results of the TLC analysis.

The ethanol and hexane extracts of $O$. basilicum showed three and four distinct spots with $R_{\mathrm{f}}$ values between 0.53 and 0.89 and 0.49 and 0.95 , respectively. The number of spots indicating the separated components in both the ethanol and hexane extracts of $O$. basilicum was less when compared to the phytochemicals identified to be present in each fruit extract at the given mobile phase. This means that some of the components coeluted in mixtures or did not elute on the TLC plate because of the use of less polar solvent system as the mobile phase. It may be necessary to employ two-dimensional TLC, column chromatography, or high-pressure liquid chromatography (HPLC) to achieve complete separation of the components.
TABLE 4: IC $_{50}$ of hydrogen peroxide radical scavenging activity of extracts of $O$. basilicum.

\begin{tabular}{lc}
\hline Sample & $\mathrm{IC}_{50}(\mu \mathrm{g} / \mathrm{mL})$ \\
\hline Gallic acid (reference standard) & $204.4 \pm 0.65$ \\
Ethanol extract & $623.5 \pm 0.27$ \\
Hexane extract & $>1000.0$ \\
\hline
\end{tabular}

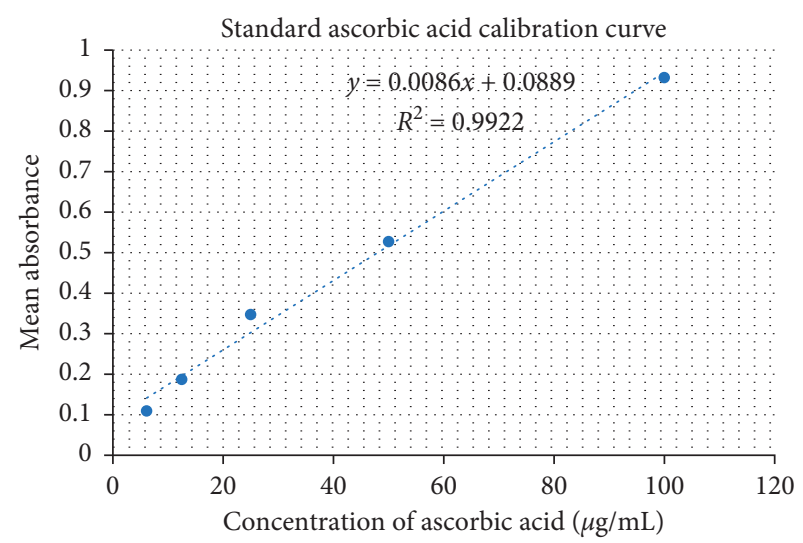

FIgURE 4: Mean absorbance of $\mathrm{PMo}_{4}^{\mathrm{V}} \mathrm{Mo}_{8}^{\mathrm{VI}} \mathrm{O}_{40}^{7-}$ (formed in ascorbic acid solution) against concentration of ascorbic acid solution.

TABLE 5: Total antioxidant capacity of ethanol and hexane extracts expressed as gAAE.

\begin{tabular}{lc}
\hline Sample & TAC $(\mathrm{gAAE} / 100 \mathrm{~g})$ \\
\hline Ethanol extract & $37.48 \pm 0.09$ \\
Hexane extract & $18.81 \pm 0.12$ \\
\hline
\end{tabular}

TAC: total antioxidant capacity; AAE: ascorbic acid equivalent.

TABLE 6: Constituents of O. basilicum extracts as determined using TLC.

\begin{tabular}{lcc}
\hline Components & \multicolumn{2}{c}{${\text { Retardation factor, } R_{\mathrm{f}}}^{\mathrm{a}}$} \\
& Ethanol extract $^{\mathrm{a}}$ & Hexane extract \\
\hline A & 0.53 & 0.49 \\
B & 0.69 & 0.64 \\
C & 0.89 & 0.71 \\
D & ND & 0.95
\end{tabular}

ND: not detected. ${ }^{a}$ Ethanol extract showed only 3 spots.

3.7. Column Chromatographic Separation. The least polar component of the hexane extract of $O$. basilicum was separated using hexane as a mobile phase (Table 7).

The separated fraction $\mathrm{A}$, having a $R_{\mathrm{f}}$ value of 0.95 using hexane/ethyl acetate $(9: 1)$ as the mobile phase, was further analyzed using FTIR analysis.

3.8. FTIR Analysis. FTIR analysis was performed on the purified component obtained from hexane extract using column chromatographic separation. The results are presented in Figure 5 and Table 8.

The wave numbers around 2958 to $2851 \mathrm{~cm}^{-1}$, $1462 \mathrm{~cm}^{-1}$, and $1378 \mathrm{~cm}^{-1}$ positions of the spectrum are characteristic of aliphatic $(\mathrm{C}-\mathrm{H})$ and $\mathrm{C}-\mathrm{H}, \mathrm{C}-\mathrm{C}$, and $\mathrm{C}-\mathrm{O}$ 
TABLE 7: Chromatographic separation of fraction A collected using hexane as the mobile phase.

\begin{tabular}{lc}
\hline Components & Retardation factor, $R_{\mathrm{f}}$ \\
\hline $\mathrm{A}$ & 0.95 \\
\hline
\end{tabular}

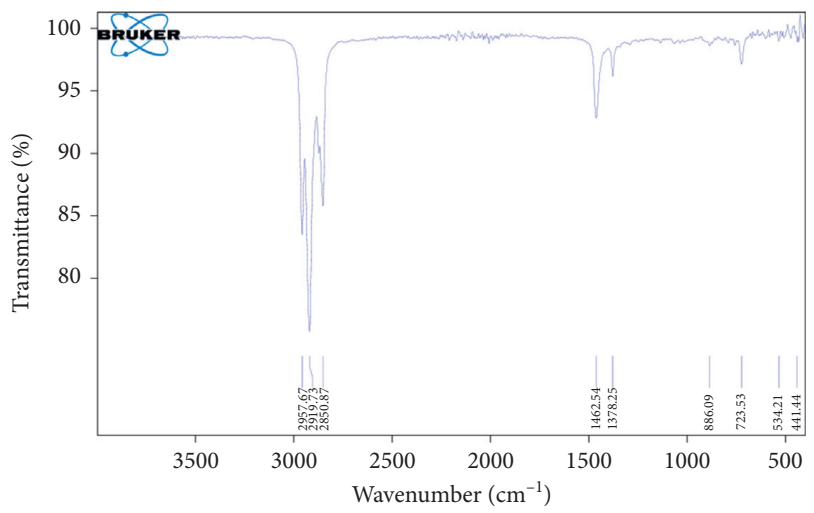

FIGURE 5: FTIR spectrum of fraction A from the hexane extract of O. basilicum.

TABLE 8: FTIR interpretation of purified fraction A from hexane extract of $O$. basilicum.

Fraction A

\begin{tabular}{lcc}
$\begin{array}{l}\text { Peak value } \\
\left(\mathrm{cm}^{-1}\right)\end{array}$ & Functional group & Inference \\
\hline 2958 to 2851 & $\begin{array}{c}\text { C-H stretch } \\
\text { C-H, C-O, and C-C } \\
\text { bend/stretch }\end{array}$ & $\begin{array}{c}\text { The functional groups show } \\
\text { highly saturated compound }\end{array}$ \\
\hline
\end{tabular}

stretching, and bending functional groups [41]. These functional groups show that fraction $\mathrm{A}$ is a highly saturated compound. This level of saturation of fraction A could be attributed to the identified secondary metabolites such as steroids, diterpenes, and/or terpenoids from the phytochemical screening test. Further structural identification and elucidation is ongoing in our research laboratory.

\section{Conclusions}

The ethanol and hexane extracts of O. basilicum showed the presence of varying secondary metabolites including alkaloids, diterpenes, flavonoids, glycosides, phenols, steroids, tannins, and terpenoids. The ethanol and hexane extracts of $O$. basilicum contain promising bioactive phytocomponents that possess anthelminthic, antioxidant, and anti-inflammatory activity. Further studies are ongoing in our laboratory towards isolation, characterization, identification, and determination of biological activities of the isolates from the fruits of $O$. basilicum.

\section{Data Availability}

The data used to support the findings of this study are included within the article.

\section{Disclosure}

Part of this work was presented as a poster at the " 8 th Ghana Science Association Research Seminar and Poster Presentations" and "8th College of Health Sciences \& 12th Convention of Biomedical Research Ghana joint Scientific Conference held at the Kwame Nkrumah University of Science and Technology, Kumasi, Ghana, in May and July 2019.

\section{Conflicts of Interest}

The authors declare that there are no conflicts of interest regarding the publication of this paper.

\section{Acknowledgments}

The authors are grateful to the Departments of Chemistry and Pharmaceutical Microbiology as well as the Central Laboratory of KNUST for the use of their facilities for this study. The authors acknowledge Mr. Francis Amankwaah of the Department of Pharmaceutical Microbiology, KNUST, for technical support.

\section{References}

[1] D. S. Fabricant and N. R. Farnsworth, "The value of plants used in traditional medicine for drug discovery," Environmental Health Perspectives, vol. 109, no. 1, pp. 69-75, 2001.

[2] P. Tiwari, B. Kumar, M. Kaur, G. Kaur, and H. Kaur, "Phytochemical screening and extraction: a review," Internationale Pharmaceutica Sciencia, vol. 1, no. 1, pp. 98-106, 2011.

[3] World Health Organization, The World Medicines Situation 2011-Traditional Medicines: Global Situation, Issues and Challenges, World Health Organization, Geneva, Switzerland, 2011.

[4] V. De Luca, V. Salim, S. M. Atsumi, and F. Yu, "Mining the biodiversity of plants: a revolution in the making," Science, vol. 336, no. 6089, pp. 1658-1661, 2012.

[5] A. A. Koparde, R. C. Doijad, and C. S. Magdum, "Natural products in drug discovery," in Pharmacognosy-Medicinal Plants, pp. 1-20, IntechOpen, London, UK, 2019.

[6] A. Acheampong, M. Badu, and A. Y. Agyemang, "Comparative total phenolics and antioxidant activities of Xanthosoma colocasia, Solanum torvum and Allium ascalonicum L," International Journal of Chemical Sciences, vol. 2, pp. 73-79, 2016.

[7] A. Acheampong, S. Okyem, C. Osei Akoto, and A. K. Baah, "Antioxidant, antimicrobial and FTIR analysis of methanol root extract of Cnestis ferruginea and ethanol root extract of Citrus limon," Journal of Pharmacognosy and Phytochemistry, vol. 7, pp. 2938-2946, 2018.

[8] A. R. Williams, C. Fryganas, A. Ramsay, I. Mueller-Harvey, and S. M. Thamsborg, "Direct anthelmintic effects of condensed tannins from diverse plant sources against Ascaris suum," PLoS One, vol. 9, no. 5, Article ID e97053, 2014.

[9] WHO, "Soil-transmitted-helminth-infections," WHO, 2019, https://www.who.int/news-room/fact-sheets/detail/ soil-transmitted-helminth-infections.

[10] A. Rajani, K. Hemamalini, D. Satyavati, S. K. A. Begum, and N. Saradhi, "Anthelmintic activity of methanolic extract of 
rhizome of Picrorrhiza kurroa royal Ex. benth," International Research Journal of Pharmacy, vol. 4, no. 8, pp. 143-144, 2013.

[11] J. A. Van Wyk, M. O. Stenson, J. S. Van Der Merwe, R. J. Vorster, and P. G. Viljoen, "Anthelmintic resistance in South Africa: surveys indicate an extremely serious situation in sheep and goat farming," Onderstepoort Journal of Veterinary Research, vol. 66, pp. 273-284, 1999.

[12] K. Santhi and R. Sengottuvel, "Qualitative and quantitative phytochemical analysis of Moringa concanensis Nimmo," International Journal of Current Microbiology and Applied Sciences, vol. 5, no. 1, pp. 633-640, 2016.

[13] A. Bilal, N. Jahan, A. Ahmed, S. N. Bilal, S. Habib, and S. Hajra, "Phytochemical and pharmacological studies on Ocimum basilicum Linn-a review," International Journal of Current Research and Review, vol. 4, no. 23, pp. 74-83, 2012.

[14] K. R. Kirtikar and B. D. Basu, Indian Medicinal Plants with Illustrations, Vol. VIII, Oriental Enterprises, Uttaranchal, India, 2nd edition, 2003.

[15] C. P. Khare, Indian Medicinal Plants: An Illustrated Dictionary, Springer Science \& Business Media, Berlin, Germany, 2008.

[16] R. P. Rastogi and B. N. Mehrotra, Compendium of Indian Medicinal Plants, Central Drug Research Institute, Lucknow, India, 1990.

[17] C. G. Bihari, M. Behera, J. P. Kumar, and T. S. Kumar, "Pharmacognostical and phytochemical investigation of various tulsi plants available in south eastern Odisha," International Journal of Research in Pharmaceutical and Biomedical Sciences, vol. 2, no. 2, pp. 605-610, 2011.

[18] S. M. A. Razavi, S. A. Mortazavi, L. Matia-Merino, S. H. Hosseini-Parvar, A. Motamedzadegan, and E. Khanipour, "Optimisation study of gum extraction from basil seeds (Ocimum basilicumL.)," International Journal of Food Science \& Technology, vol. 44, no. 9, pp. 1755-1762, 2009.

[19] J.-I. Azuma and M. Sakamoto, "Cellulosic hydrocolloid system presents in seed of plants," Trends in Glycoscience and Glycotechnology, vol. 15, no. 81, pp. 1-14, 2003.

[20] A. E. González-Stuart, D. Prakash, and C. Gupta, "Phytochemistry of plants used in traditional medicine," in Phytochemicals of Nutraceutical Importance, p. 288, CABI, Wallingford, UK, 2014.

[21] M. S. Mohammed, W. J. A. Osman, E. A. E. Garelnabi, Z. Osman, and J. August, "Secondary metabolites as antiinflammatory agents," Pharmacognosy Journal, vol. 3, pp. 275-285, 2014.

[22] G. E. Trease and W. C. Evans, Pharmacognosy, W.B. Sanders Company Ltd., New York, NY, USA, 16th edition, 2009.

[23] E. O. Ajaiyeoba, P. A. Onocha, and O. T. Olarenwaju, "In vitro anthelmintic properties of Buchholzia coriaceae and Gynandropsis gynandra extracts," Pharmaceutical Biology, vol. 39, no. 3, pp. 217-220, 2001.

[24] C. Sree Kumari, N. Yasmin, M. R. Hussain, and M. Babuselvam, "In vitro anti-inflammatory and anti-arthritic property of Rhizopra mucronata leaves," International Journal of Pharmaceutical Sciences and Research, vol. 6, pp. 482-485, 2015.

[25] C. Sánchez-Moreno, J. A. Larrauri, and F. Saura-Calixto, "A procedure to measure the antiradical efficiency of polyphenols," Journal of the Science of Food and Agriculture, vol. 76, no. 2, pp. 270-276, 1998.

[26] D. Mukhopadhyay, P. Dasgupta, D. Sinha Roy et al., "A sensitive in vitro spectrophotometric hydrogen peroxide scavenging assay using 1,10-phenanthroline," Free Radicals and Antioxidants, vol. 6, no. 1, pp. 124-132, 2016.
[27] P. Prieto, M. Pineda, and M. Aguilar, "Spectrophotometric quantitation of antioxidant capacity through the formation of a phosphomolybdenum complex: specific application to the determination of vitamin E," Analytical Biochemistry, vol. 269, no. 2, pp. 337-341, 1999.

[28] Y. Zhao, A. D. Slepkov, C. O. Akoto, R. Mcdonald, F. A. Hegmann, and R. R. Tykwinski, "Synthesis, structure, and nonlinear optical properties of cross-conjugated perphenylatediso-polydiacetylenes," Chemistry-A European Journal, vol. 11, no. 1, pp. 321-329, 2005.

[29] C. Osei Akoto and J. D. Rainier, "Harnessing glycal-epoxide rearrangements: the generation of the $\mathrm{AB}, \mathrm{EF}$, and IJ rings of adriatoxin," Angewandte Chemie International Edition, vol. 47, no. 42, pp. 8055-8058, 2008.

[30] S. Rai, H. Ghosh, and M. Basheer, "Phytochemical characterization and antioxidative property of Ocimum canum: effect of ethanolic extract of leaves and seeds on basic immunologic and metabolic status of male rats," The Journal of Immunology, vol. 1, 2016.

[31] D. E. Okwu, "Phytochemical and vitamin content of indigenous spices of South Eastern Nigeria," Journal of Sustainable Agriculture and the Environment, vol. 6, pp. 30-34, 2004.

[32] P. K. Boniface, S. B. Ferreira, and C. R. Kaiser, "Recent trends in phytochemistry, ethnobotany and pharmacological significance of Alchornea cordifolia (Schumach. \& Thonn.) Muell. Arg," Journal of Ethnopharmacology, vol. 191, pp. 216-244, 2016.

[33] S. A. Gaikwad, A. A. Kale, B. G. Jadhav, N. R. Deshpande, and J. P. Salvekar, "Anthelmintic activity of Cassia auriculata L. extracts, in vitro study," The Journal of Natural Product and Plant Resources, vol. 1, 2011.

[34] D. N. Raut, S. C. Pal, and S. C. Mandal, "Anthelmintic potential of Dendrophthoe falcata etting. (lf) leaf," International Journal of Pharmaceutical Research and Development, vol. 6, no. 2, p. s, 2009

[35] D. E. Cabardo Jr. and H. P. Portugaliza, "Anthelmintic activity of Moringa oleifera seed aqueous and ethanolic extracts against Haemonchus contortus eggs and third stage larvae," International Journal of Veterinary Science and Medicine, vol. 5, no. 1, pp. 30-34, 2017.

[36] K. Karthik, B. R. Kumar, K. R. V. Priya, S. K. Kumar, and R. S. B. Rathore, "Evaluation of anti-inflammatory activity of canthium parviflorum by in-vitro method," Indian Journal of Research in Pharmacy and Biotechnology, vol. 5674, pp. 2320-2322, 2013.

[37] F.-L. Song, R.-Y. Gan, Y. Zhang, Q. Xiao, L. Kuang, and H.-B. Li, "Total phenolic contents and antioxidant capacities of selected Chinese medicinal plants," International Journal of Molecular Sciences, vol. 11, no. 6, pp. 2362-2372, 2010.

[38] T. Ibrahim, K. Muluh, and A. Alexander, "Phytochemical screening, antioxidant and antibacterial activities of Commiphora kerstingii," International Biological and Biomedical Journal, vol. 2, 2016.

[39] S. B. Nimse and D. Pal, "Free radicals, natural antioxidants, and their reaction mechanisms," RSC Advances, vol. 5, no. 35, pp. 27986-28006, 2015.

[40] J. Du, J. J. Cullen, and G. R. Buettner, "Ascorbic acid: chemistry, biology and the treatment of cancer," Biochimica et Biophysica Acta (BBA)-Reviews on Cancer Biochim, vol. 1826, no. 2, pp. 443-457, 2012.

[41] C. Osei Akoto and J. D. Rainier, "Concise seven-membered oxepene/oxepane synthesis-structural motifs in natural and synthetic products," Synthesis, vol. 51, no. 18, pp. 3529-3535, 2019. 